\title{
Co-localization and Characterization of Immunoreactive Peptides Derived from Two Opioid Precursors in Guinea Pig Adrenal Glands ${ }^{1}$
}

\author{
CHRISTOPHER J. EVANS, ${ }^{2}$ ELIZABETH ERDELYI, JOAN HUNTER, AND JACK D. BARCHAS
}

Nancy Pritzker Laboratory of Behavioral Neurochemistry, Department of Psychiatry and Behavioral Sciences, Stanford University School of Medicine, Stanford, California 94305

\begin{abstract}
Peptides derived from both proenkephalin and prodynorphin have been identified in guinea pig adrenal medulla. In extracts of whole adrenal glands radioimmunoassays directed to the prodynorphin-derived peptides $\alpha$-neoendorphin, dynorphin $A$, and dynorphin $B$ detected high concentrations of immunoreactive material ranging from 113 to $216 \mathrm{pmol} /$ gm. The concentrations measured by radioimmunoassays directed to the proenkephalin products met-enkephalin-ArgGly-Leu and met-enkephalin-Arg-Phe were 878 and 484 $\mathrm{pmol} / \mathrm{gm}$, respectively. No metorphamide or dynorphin(1-8) could be detected in the adrenals. Leucine-enkephalin immunoreactivity which can be generated from either prodynorphin or proenkephalin could also be measured in the extracts. Gel filtration showed the immunoreactive material, with the exception of that measured by the $\alpha$-neoendorphin radioimmunoassay, to be predominantly of high molecular weight ranging from $M_{\mathrm{r}}=3,000$ to 12,000 . Immunocytochemistry, using well characterized antisera to $\alpha$-neoendorphin and met-enkephalin-Arg-Gly-Leu, demonstrated that the prodynorphin and proenkephalin products were present in the same cells in the medulla region of the gland. The results show that two opioid peptide precursors can be localized in the same cells and exhibit some common features in their processing. As a relatively homogeneous, localized system, the guinea pig adrenal gland should prove a valuable, in vivo model for the study of co-localized opioid precursors.
\end{abstract}

At present there are three known protein precursors that give rise to endogenous opioid peptides. These are pro-opiomelanocortin (Nakanishi et al., 1979), which contains the sequence of adrenocorticotropic hormone and $\beta$-endorphin, prodynorphin (Kakidani et al., 1982), and proenkephalin (Comb et al., 1982; Noda et al., 1982). The opioid peptides generated by intracellular processing of these precursors vary considerably with regard to their proteolytic stability, receptor selectivity, and potency. Although there are considerable species differences, fragments of all three precursor proteins have been shown to be present in the adrenal gland. All mammals investigated contain proenkephalin fragments which by immunocytochemistry have been shown to be present in chromaffin cells and are co-localized and co-secreted with adrenalin (Viveros et al., 1979).

Received February 8, 1985; Revised April 22, 1985;

Accepted May 23, 1985

This work was supported by National Institute of Mental Health Grant MH 23861. We thank Irene Inman for technical assistance with the radioimmunoassays and Sue Poage for preparing the manuscript.

${ }^{2}$ To whom correspondence should be addressed.
Human and monkey adrenal glands contain pro-opiomelanocortinderived peptides in addition to proenkephalin (Nakao et al., 1981; Evans et al., 1983a), but the specific cellular localization has not been established. Although dynorphin (1-13)-like immunoreactivity can be detected in bovine adrenal medulla (Day et al., 1982), no other prodynorphin-derived products can be found in this bovine tissue (Evans et al., 1983b). Guinea pig adrenal is unusual in that it is the only species in which we detect prodynorphin as well as proenkephalin fragments (Evans et al., 1983b). In this study we have analyzed the processing products and distribution of the opioid precursor products stored in the guinea pig adrenal gland.

\section{Materials and Methods}

All peptides used in this study were obtained from Peninsula Laboratories (San Carlos, CA). Antisera to the proenkephalin, prodynorphin, and proopiomelanocortin fragments were generated in rabbits by subcutaneous injection of thyroglobulin conjugates (details of the procedures used have been published (Weber et al., 1982b)). Radioimmunoassays (RIAs) were performed using iodinated tracer peptides and bound ligand separated from unbound using a second antibody precipitation procedure (Weber et al.,

TABLE I

Determination of proenkephalin-, pro-opiomelanocortin-, and prodynorphin-derived peptide concentrations by RIA

Acid/acetone extracts were prepared for RIA as described under "Materials and Methods." Concentrations are expressed for the average of five whole adrenal glands. The asterisked peptides represent RIAs specifically recognizing single arginine cleavage products based on the bovine proenkephalin and porcine prodynorphin cDNA sequences. Leu-enkephalin immunoreactivity, although listed under proenkephalin products, could be generated from prodynorphin.

\begin{tabular}{lc}
\hline \multicolumn{1}{c}{ RIA } & $\begin{array}{c}\text { Concentration } \\
\text { (pmol/gm) }\end{array}$ \\
\hline Prodynorphin & \\
$\alpha$-Neoendorphin (Weber et al., 1982C) & $216 \pm 30.9$ \\
Dynorphin A ( ${ }^{-17}$ (Weber et al., 1982a) & $129 \pm 13.2$ \\
*Dynorphin B & $113 \pm 7.0$ \\
* Dynorphin (1-8) (Weber et al., 1982a) & $\leq 2$ \\
Proenkephalin & $209 \pm 28.3$ \\
Leu-enkephalin & $878 \pm 162$ \\
Met-enkephalin in RGL & $484 \pm 105$ \\
Met-enkephalin RF & $\leq 1$ \\
*Metorphamide (Weber et al., 1983) & $\leq 2$ \\
Pro-opiomelanocortin & $\leq 1$ \\
$\beta$-Endorphin (middle region) (Evans et al., 1983a) & $\leq 1$ \\
ACTH (Evans et al., 1983a) & \\
$\alpha$-MSH (Evans et al., 1982) & \\
\hline
\end{tabular}


Figure 1. Gel filtration analysis on Sephadex $\mathrm{G} 75$ of the proenkephalin-related immunoreactive peptides in guinea pig adrenal glands. An acid/acetone extract of the equivalent of one adrenal gland containing $10,000 \mathrm{cpm}$ each of the iodinated markers was loaded onto the column. Aliquots from each fraction were analyzed for immunoreactive Met-enkephalin-Arg-Phe and Metenkephalin-Arg-Gly-Leu. The markers were: $A$, exclusion; $B,{ }^{125}$ - $\beta$-lipotropin; $C,{ }^{125}-\beta$ endorphin; $D,{ }^{125}$ - $\alpha$-neoendorphin; $E,{ }^{125}$ Leuenkephalin.

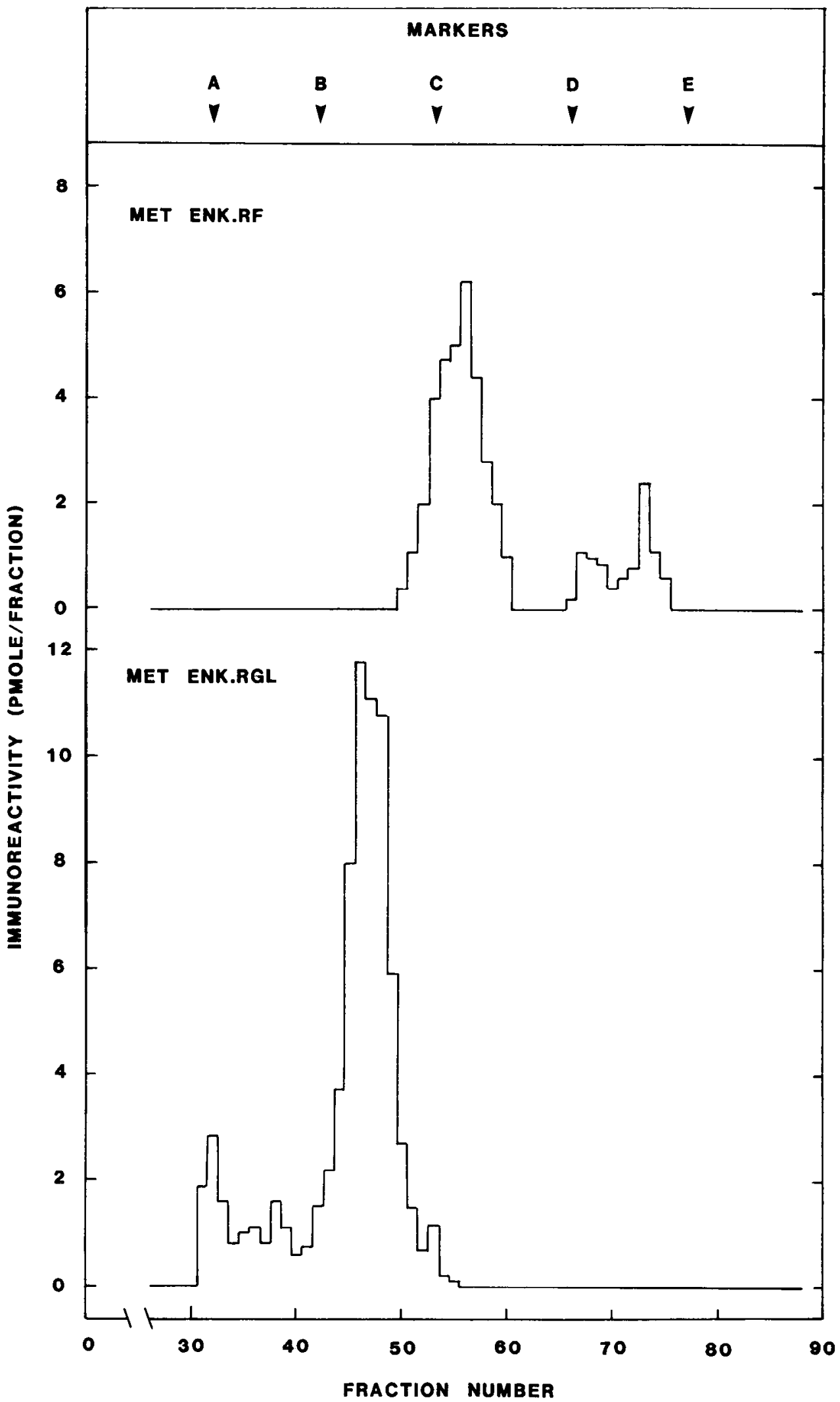

$1982 \mathrm{a}, \mathrm{b})$. The properties of the majority of the RIAs used in this study have been described and are referenced in Table I. A brief summary of the unpublished RIAs is as follows. The Met-enkephalin-Arg-Gly-Leu antisera were used at a dilution of $1: 30,000$ and the $\mathrm{IC}_{50}$ was typically 800 to $900 \mathrm{pm}$.
The assay cross-reacted less than $0.01 \%$ with dynorphin(1-8), Met-enkephalin-Arg-Phe, Met-enkephalin, and $\alpha$-neoendorphin. The Leu-enkephalin antisera were used at a dilution of $1: 50,000$ and the $\mathrm{IC}_{50}$ ranged between 800 and $1000 \mathrm{pm}$. The assay cross-reacted less than $0.01 \%$ with dynorphin(1-8), 


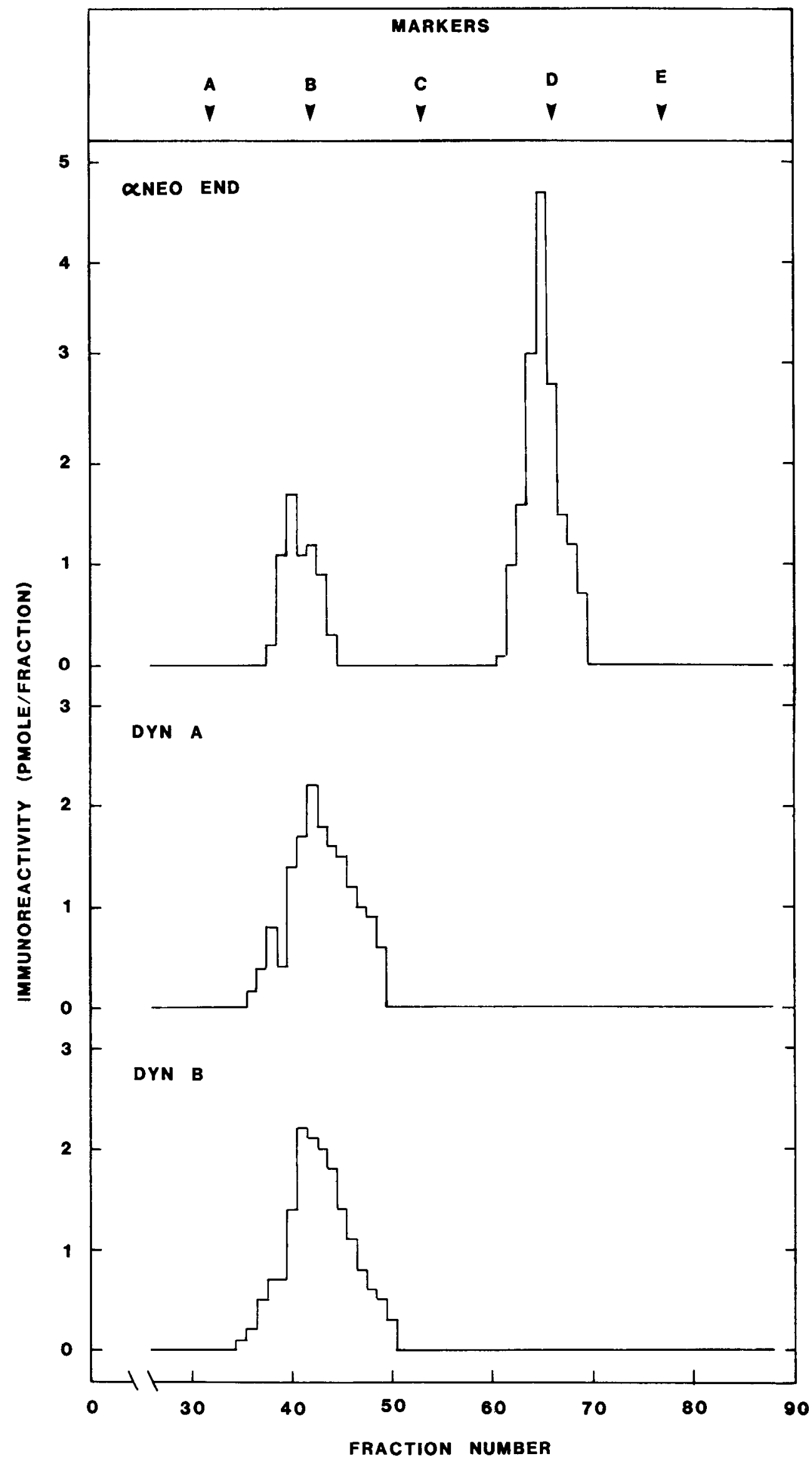

Figure 2. Analysis of the prodynorphinimmunoreactive products in guinea pig adrenals. Preparation of tissue, chromatography conditions, and iodinated column markers were identical to those in Figure 1. Fractions were analyzed using RIAs directed to $\alpha$ neoendorphin, dynorphin $\mathrm{A}(1-17)$, and dynorphin $\mathrm{B}$ 


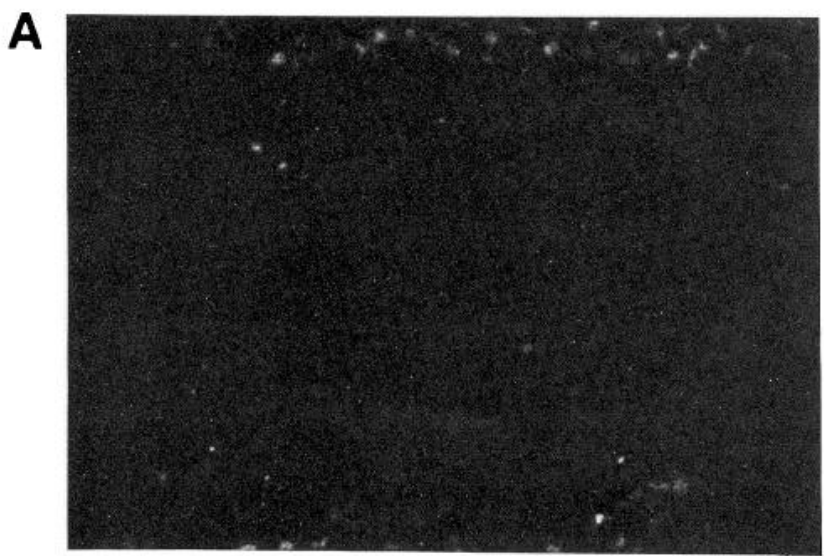

B

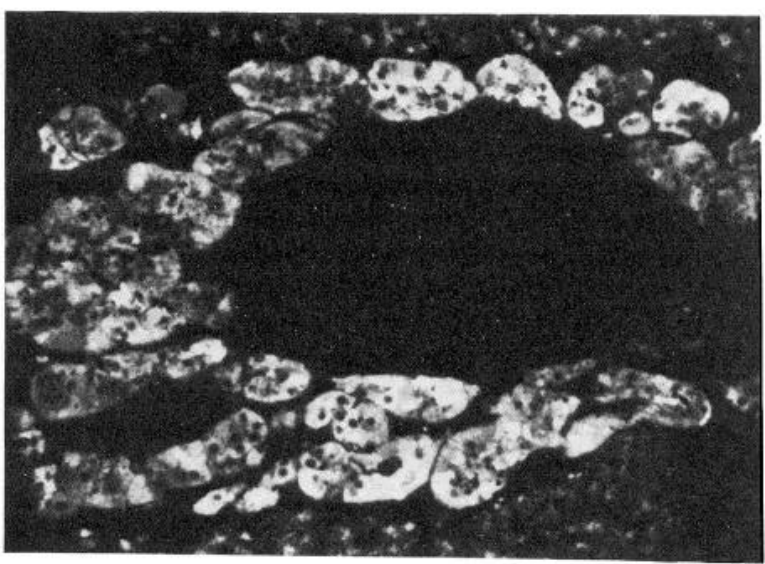

C

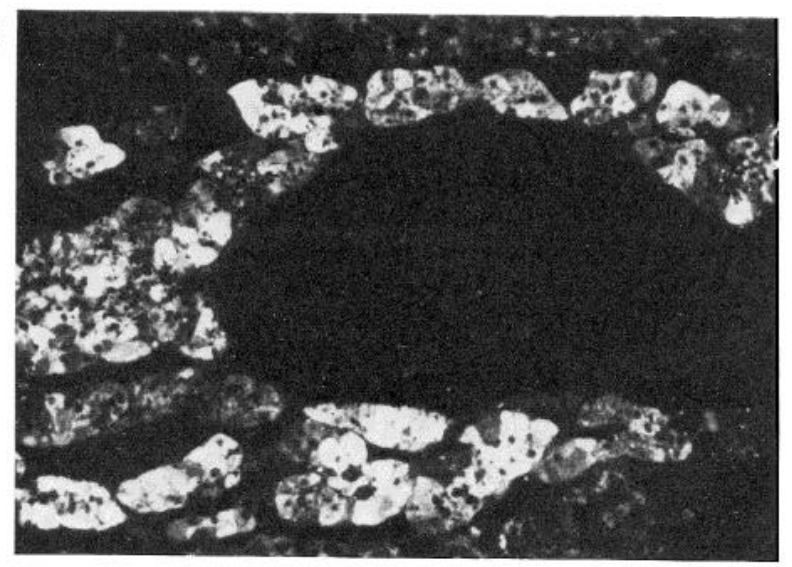

D

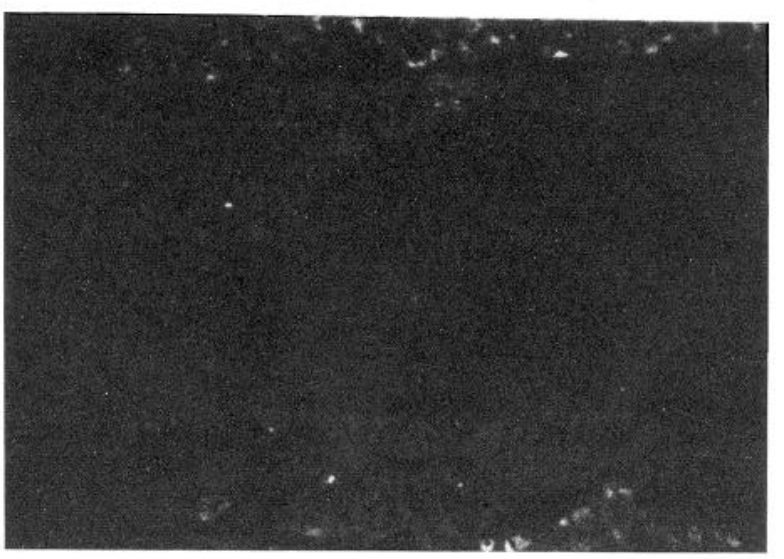

Tyr-Gly-Gly-Phe, and Met-enkephalin-Arg-Gly-Leu but had a $2 \%$ cross-reactivity with Met-enkephalin. The Met-enkephalin-Arg-Phe antisera were used at dilution of $1: 3,000$, the $\mathrm{IC}_{50}$ ranging from 1 to $1.5 \mathrm{~nm}$. Met-enkephalin-Arg Phe-amide cross-reacted $2 \%$ but Met-enkephalin, Met-enkephalin-Arg-GlyLeu, dynorphin(1-8), and Met-enkephalin-Arg-Arg cross-reacted less than $0.1 \%$. The dynorphin B antisera were used at a dilution of $1: 150,000$ and had a $1 \%$ cross-reactivity with dynorphin B-29 but less than $0.5 \%$ crossreactivity with $\alpha$-neoendorphin, dynorphin(1-17), and dynorphin(1-8). The $\mathrm{IC}_{50}$ was between 200 and 400 pM.

Adrenal glands were dissected from male Hartley albino guinea pigs (200 to $300 \mathrm{gm}$ ) sacrificed by decapitation. Glands were extracted in $5 \mathrm{w} / \mathrm{v}$ of acetone: $0.2 \mathrm{~N} \mathrm{HCl}(75: 25)$. Previously we have demonstrated that extraction using acid/acetone gives very good recoveries of opioid peptides from brain tissues (from 59 to $80 \%$ ) (Weber et al., 1982a). Recoveries of synthetic ${ }^{125}$ peptides added to the guinea pig adrenals prior to homogenization was greater than $78 \%$ for all peptides to which the assays were developed. The acid/acetone extracts were spun at $10,000 \times g$ for $20 \mathrm{~min}$, the supernatant was evaporated to dryness, and the residue was redissolved in neutral buffer in preparation for RIA. For gel filtration, the residue was dissolved in $25 \%$ acetic acid and chromatographed in a $0.9 \times 120 \mathrm{~cm}$ column packed with Sephadex G75 (fine). The column was equilibrated and eluted with $25 \%$ acetic acid containing $0.1 \%$ thiodiglycol. Fractions of $1.5 \mathrm{ml}$ were collected, and aliquotes were evaporated to dryness and analyzed by RIA.

For immunohistofluorescence, adrenals were fixed by immersion in $4 \%$ formaldehyde at $4^{\circ} \mathrm{C}$ overnight and then frozen at $-80^{\circ} \mathrm{C}$ following cryogenic protection in $5 \%$ sucrose. Frozen $4.5-\mu \mathrm{m}$ sections were cut on a Hacker model 5030 microtome and incubated with antisera diluted 1:400. Bound antiserum was visualized with fluorescein-conjugated goat anti-rabbit lgG (see Weber et al., 1982d, for details of the procedure). Blocking controls were performed using $10 \mu \mathrm{M}$ peptide incubated with the primary antisera.

\section{Results and Discussion}

Whole guinea pig adrenals were extracted with acid/acetone and the concentrations of a series of proenkephalin-, pro-opiomelanocortin-, and prodynorphin-derived peptides were determined by RIA. The results are shown in Table I. The extracts were found to contain Met-enkephalin-Arg-Gly-Leu- and Met-enkephalin-Arg-Phe-immunoreactive material showing the presence of proenkephalin-derived peptides. In addition, dynorphin A, dynorphin B, and $\alpha$-neoendorphin immunoreactivity could be detected, indicating that guinea pig adrenals also contain fragments of prodynorphin. However, there was no evidence for pro-opiomelanocortin-derived peptides. The presence of both prodynorphin- and proenkephalin-derived peptides prompted the search for more extensive processing fragments of these precursors such as metorphamide and dynorphin(1-8), which are both present in guinea pig brain (Sonders et al., 1984; C. J. Evans andE. Weber, unpublished observation). Although both these opioid peptides are readily extracted by acid/acetone, neither could be detected by RIA in guinea pig adrenal extracts, indicating that either the enzymes responsible for the conversion to these products are absent or they have low activity in the guinea pig adrenal. If the sequence of guinea pig prodynorphin and proenkephalin is conserved at the cleavage site generating the $\mathrm{C}$-termini of metorphamide and dynorphin(1-8), the processing enzymes would act in both precursors at an $X$-Arg-Pro sequence where $X$ is a neutral amino acid.

The prodynorphin- and proenkephalin-immunoreactive products were analyzed by gel filtration chromatography (Figs. 1 and 2). Met-

Figure 3. The histological location of the Met-enkephalin-Arg-Gly-Leu and $\alpha$-neoendorphin immunoreactivity in guinea pig adrenal glands. $A$ to $D$ represent sequential $4.5-\mu \mathrm{m}$ sections through the gland. $A$ was incubated with $\alpha$-neoendorphin antisera containing $10 \mu \mathrm{M} \alpha$-neoendorphin, and $B$ was incubated with antisera alone. $C$ was stained with Met-enkephalin-Arg-GlyLeu antisera and $D$ was stained with antisera plus $10 \mu \mathrm{M}$ Met-enkephalinArg-Gly-Leu. The $\alpha$-neoendorphin staining could not be blocked by $10 \mu \mathrm{M}$ dynorphin A(1-17), dynorphin B, Met-enkephalin-Arg-Phe, Met-enkephalinArg-Gly-Leu or Leu-enkephalin but was blocked by $\alpha$-neoendorphin $(A)$. The Met-enkephalin-Arg-Gly-Leu staining was not blocked by $10 \mu \mathrm{M}$ dynorphin $\mathrm{A}(1-17)$, dynorphin B, Met-enkephalin-Arg-Phe, or $\alpha$-neoendorphin but was blocked by Met-enkephalin-Arg-Gly-Leu $(D)$. 
enkephalin-Arg-Phe and Met-enkephalin-Arg-Gly-Leu assays recognized material of high molecular weight which would be comparable with the previously characterized 3.6-kilodalton (Stern et al., 1981) and 5.3-kilodalton species found in bovine adrenal (Jones et al. 1982). With regard to the prodynorphin markers, the major $\alpha$ neoendorphin-immunoreactive peak eluled at the position of ${ }^{125}-\alpha$ neoendorphin. However, the dynorphin A and dynorphin B immunoreactivity eluted in an almost identical pattern at an extrapolated $M_{\mathrm{r}}=8,000$ to 10,000 . The dynorphin B RIA is specific for the Cterminus of dynorphin $B$ and has very low cross-reactivity with dynorphin B-29. If this region of prodynorphin is conserved in the guinea pig as it is in the rat and bovine precursor (personal communication from $\mathrm{O}$. Civelli, J. Douglas, and E. Herbert, University of Oregon, who have recently sequenced rat prodynorphin cDNA; Kakidani et al., 1982), recognition by the RIA would require cleavage of the precursor at a single arginine residue. The molecular weight estimates and immunoproperties would suggest that this single arginine cleavage occurs in preference to the processing site between dynorphin $B$ and dynorphin $A$, a lysyl-arginine in bovine prodynorphin.

The location of the prodynorphin- and proenkephalin-derived pcp tides was determined by immunohistofluorescence. Sections were stained with antisera directed to Met-enkephalin-Arg-Gly-Leu, a proenkephalin marker, or $\alpha$-neoendorphin, a prodynorphin marker.

The immunofluorescent staining of both antisera was confined to the medulla region of the gland, as shown in Figure 3 . The thin sectioning cut through the same cells several times and by staining adjacent alternate sections with antisera directed to Met-enkephalinArg-Gly-Leu and $\alpha$-neoendorphin; both antisera were shown to stain the same cells (Fig. 3). Extensive blocking controls were conducted to verify the specificity of each antiserum (see legend to Fig. 3). The data show that proenkephalin and prodynorphin products are colocalized in this tissue. This conclusion was supported by immunohistochemistry using Met-enkephalin-Arg-Phe, dynorphin A, and dynorphin $B$ antisera, all of which gave similar staining patterns (data not shown)

These observations raise a very interesting question as to whether products of these two opioid precursors coexist in the same granules and consequently would be secreted under the same control and available for processing by the same enzymes. The incomplete processing of both opioid precursors would be consistent with cogranular storage. However, appropriate electron microscopy studies are required to fully address this question. Prodynorphin- and proenkephalin-like immunohistofluorescence has also been observed in the same cells in rat brainstem (Basbaum and Fields, 1984). The significance of co-localization of these two opioid precursors is unclear but may indicate multiopiate receptor targets for these particular neurons.

The immunohistofluorescence shows that the opioid precursor fragments are confined to the medulla region of the gland. Consequently, the RIA results in Table I, which are for whole gland extracts, can be multiplied 4 to 10 times to estimate the concentration in the medulla (the multiplication factor was deduced from areas of medulla versus cortex in lissue sections). The correcled concentrations show that the guinea pig adrenal medulla is a very rich source of both proenkephalin- and prodynorphin-derived peptides.

The isolation of the adrenal gland from other neuronal tissue allows quantitative biochemical measurement of the precursors at the peptide as well as the mRNA level. Indeed, in collaboration with Dr. J. Eberwine at Stanford Medical Center, we have measured and characterized by Northern blots both prodynorphin and proenkephalin mRNA in guinea pig adrenal gland (probes were kindly supplied by Dr. E. Herbert's group at the University of Oregon). Consequently, experiments relating to the control of expression of opioid precursors can be studied in a model system from which considerable information has been gathered on the physiology and pharmacology. Previous studies utilizing adrenal and pituitary tissue have been limited to the analysis of expression of a single opioid system, either pro-opiomelanocortin or proenkephalin (Eipper and Mains, 1980; Eiden et al., 1984). The guinea pig adrenal model should make possible informative studies on the in vivo control of expression of two endogenous co-localized opioid precursors.

\section{References}

Basbaum, A. I., and H. L. Fields (1984) Endogenous pain control systems. Annu. Rev. Neurosci. 7: 309-338.

Comb, M., P. Seeburg, J. Adelman, L. Eiden, and E. Herbert (1982) Primary structure of the human met- and leu-enkephalin precursor and its mRNA. Nature 295: 663-666.

Day, R., D. Denis, J. Barabe, S. St-Pierre, and S. Lemaire (1982) Dynorphin in bovine adrenal medulla. Int. J. Pept. Protein Res. 19: 10-17.

Eiden, L. E., P. Giraud, H. -U. Affolter, E. Herbert and A. J. Hotchkiss (1984) Alternative modes of enkephalin biosynthesis regulation by reserpine and cyclic AMP in cultured chromaffin cells. Proc. Natl. Acad. Sci. U. S. A. 81 : 3949-3953.

Eipper, B., and R. Mains (1980) Structure and biosynthesis of pro-adrenocorticotropin/endorphin and related peptides. Endocr. Rev. 1: 1-27.

Evans, C. J. R. Lorenz, E. Weber, and J. D. Barchas (1982) Variants of alpha-melanocyte stimulating hormone in rat brain and pituitary: Evidence that acetylated $\alpha$-MSH exists only in the intermediate lobe of pituitary. Biochem. Biophys. Res. Commun. 106: 910-919.

Evans, C. J., E. Erdelyi, E. Weber, and J. D. Barchas (1983a) Identification of pro-opiomelanocortin derived peptides in the human adrenal medulla Science 221: 957-960.

Evans, C. J., E. Erdelyi, J. D. Barchas (1985) Opioid peptides in the adrena pituitary axis. Psychopharmacol. Bull. 21: (3) 466-471.

Jones, B. N., J. E. Shively, D. L. Kilpatrick, K. Kojima, and S. Udentriend (1982) Enkephalin biosynthetic pathway: A 5300-dalton adrenal polypeptide that terminates at its $\mathrm{COOH}$ end with the sequence [Met]enkephalinArg-Gly-Leu-COOH. Proc. Natl. Acad. Sci. U. S. A. 79: 1313-1315.

Kakidani, H., Y. Furutani, H. Takahashi, M. Noda, Y. Morimoto, T. Hirose, M Asa, S. Inayama, S. Nakanishi, and S. Numa (1982) Cloning and sequence analysis of CDNA for porcine $\beta$-neo-endorphin/dynorphin precursor. Nature 298: 245-248

Nakanishi, S., A. Inoue, T. Kita, M. Nakamura, A. C. Y. Chang, S. N. Cohen, and S. Numa (1979) Nucleotide sequence of cloned cDNA for bovine corticotropin- $\beta$-lipotropin precursor. Nature 278: 423-427.

Nakao, K., T. Yoshimasa, H. Ohtsuki, S. Oki, I. Tanaka, Y. Nakai, and $H$. Imura (1981) $\beta$-Endorphin, ACTH, and $\gamma-\mathrm{MSH}$ in human sympathoadrenal system. In Eighth International Congress of Pharmacology, Tokyo, p. 854 , Japanese Pharmacological Society, Kyoto

Noda, M, Y. Furatani, H Takahashi, M. Toyosato, T. Hirose, S. Inayama, S. Nakanishi, and S. Numa (1982) Cloning and sequence analysis of CDNA for bovine adrenal preproenkephalin. Nature 295: 202-206.

Sonders, M., J. D. Barchas, and E. Wcber (1984) Regional distribution of metorphamide in rat and guinea pig brain. Biochem. Biophys. Res. Com mun. 222: 892-898

Stern, A. S., B. N. Jories, J. E. Shively, S. Stein, and S. Udenfriend (1981) Two adrenal opioid polypeptides: Proposed intermediates in the process ing of proenkephalin. Proc. Natl. Acad. Sci. U. S. A. 78: 1962-1966.

Viveros, O. H., E. J. Diliberto, E. Hazum, and K. -J. Chang (1979) Opiate-like materials in the adrenal medulla: Evidence for storage and secretion with catecholamines. Mol. Pharmacol. 16: 1101-1108.

Weber, E., C. J. Evans, and J. D. Barchas (1982a) Opioid peptide dynorphin Predominance of the aminoterminal octapeptide fragment in rat brain regions. Nature 299: $77-79$

Weber, E., C. J. Evans, J. -K. Chang, and J. D. Barchas (1982b) Antibodies specific for $\alpha-N$-acetyl $\beta$-endorphins: Radioimmunoassays and detection of acetylated $\beta$-endorphins in pituitary extracts. J. Neurochem. 38: 436 477.

Weber, E., C. J. Evans, J. -K. Chang, and J. D. Barchas (1982c) Brain distributions of $\alpha$-neo-endorphin and $\beta$-neo-endorphin: Evidence for regional processing differences. Biochem. Biophys. Res. Commun. 108 81-88.

Weber, E., K. Roth, and J. D. Barchas (1982d) Immunohistochemical distribution of $\alpha$-neo-endorphin/dynorphin neuronal systems in rat brain: Evidence for colocalization. Proc. Natl. Acad. Sci. U. S. A. 79: 3062-3066.

Weber, E., F. S. Esch, P. Bohlan, S. Paterson, A. D. Corbett, A. T. McKnight, H. W. Kosterlitz, J. D. Barchas, and C. J. Evans (1983) Metorphamide: Isolation, structure and biologic activity of a novel amidated opioid octapeptide from bovine brain. Proc. Natl. Acad. Sci. U. S. A. 80: 7362-7366. 